\title{
Research on Fast Semi-Quantitative Risk Assessment Method for High Temperature and High Pressure Gas Wells
}

\author{
Mifeng Zhao, Hailong Geng, Jingcheng Zhang, Junfeng Xie, Kelin Wang \\ Petroleum Engineering Institute, Petro China Tarim Oilfield Company, Korla, Xinjiang, China \\ Email: 1ld1210@qq.com
}

How to cite this paper: Zhao, M.F., Geng, H.L., Zhang, J.C., Xie, J.F. and Wang, K.L. (2021) Research on Fast Semi-Quantitative Risk Assessment Method for High Temperature and High Pressure Gas Wells. World Journal of Engineering and Technology, 9, 100-108.

https://doi.org/10.4236/wjet.2021.91008

Received: December 14, 2020

Accepted: February 5, 2021

Published: February 8, 2021

Copyright $\odot 2021$ by author(s) and Scientific Research Publishing Inc. This work is licensed under the Creative Commons Attribution International License (CC BY 4.0).

http://creativecommons.org/licenses/by/4.0/

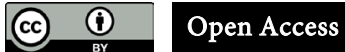

\begin{abstract}
Aiming at the problem that the existing risk assessment methods in China cannot simply and accurately assess the safety risk of gas wells, a rapid semi-quantitative risk assessment method for gas wells under high temperature and pressure is studied. Based on the rapid risk assessment method of annulus well with pressure in Chevron Company and the existing risk assessment methods, the well barrier and annulus pressure of high temperature and high pressure gas wells are fully considered. A rapid semi-quantitative risk assessment method for high temperature and high pressure gas wells is established, which takes the annulus pressure value, well service life, annulus pressure recovery after pressure relief, reservoir conditions (formation pressure, production) and well $\mathrm{CO}_{2}$ and $\mathrm{H}_{2} \mathrm{~S}$ content as the key risk indexes. The method is applied in a gas field, and the risk value and risk grade of a practical well are semi-quantitatively evaluated. The overall risk situation of the well is obtained. The research results provide important technical guidance for the safe production of gas well.
\end{abstract}

\section{Keywords}

HPHT, Semi-Quantitative, Risk Assessment, Quantitative Scoring

\section{Overview}

China's gas resources are very rich, is an important source of China's oil and gas resources supply, since 2019, China's natural gas upstream industry investment has also increased significantly, with a series of exploration found, to achieve a substantial increase in reserves and production, gas development encountered wellbore integrity problems are increasingly serious. At present, the risk degree 
evaluation of oil and gas wells in China is mostly quantitative or qualitative risk evaluation, and quantitative evaluation requires a large number of statistical data to establish a mathematical model. The operation is complicated and the qualitative evaluation method is simple. But the accuracy is poor. It is of great significance for the safe production of gas wells to propose a set of risk assessment methods that can take into account the advantages of the existing risk assessment methods and are easy to operate and have high accuracy.

In 2002, A.S. Abou-Sayed et al. analyzed the geomechanical model to evaluate the factors affecting the stability of casing [1]; in 2004, Jamal Al-Ashhab et al. established the wellbore integrity management system through the risk matrix method, and evaluated the integrity of the whole life cycle of gas wells [2]. In 2006, Soudabeh A. Noori et al. proposed the application of probability statistics and the combination of non-destructive monitoring results to evaluate the risk of pipeline corrosion to evaluate and predict the risk of boiler pipeline thinning [3]. From 2006 to 2008, foreign scholars established wellbore integrity management system under different formation conditions by risk matrix method [4] [5]; Seyed-Hosseini S M and others developed wellbore integrity management software, created wellbore integrity management methods and measures [6]; In 2009, Sultan A et al. proposed the method of quality identification and safety check of wellbore and its components in each stage of oil and gas wells [7]; in the same year, Freij-Ayoub R, et al. created axisymmetric numerical model combined with FLAC3D to study the risk assessment of casing in natural gas hydrate [8], in 2012; J. C. Dethlefs and B. Chastain of ConocoPhillips introduced a qualitative risk assessment method for wellbore integrity [9]; 2013, Feng W et al. according to the characteristics of carbon dioxide flooding gas well, established the wellbore risk assessment process and evaluation model [10]. In 2014, T. Rocha-Valadez et al. provided a quantitative analysis model with only a theoretical framework to analyze wellbore integrity [11]; from 2014 to 2016, foreign oil companies set up a risk method research team, and applied the gas well integrity evaluation system (WIMS) to qualitatively analyze the possible failure risk of gas wells in the form of risk assessment matrix [12] [13]; in 2015, Nahid Ramzali et al. conducted safety evaluation and verification of wellbore string and accessories at each stage of the life cycle of oil and gas wells [14]; in 2016, Brandt $\mathrm{H}$ et al. used quantitative risk assessment methods for well construction and management [15].

The above scholars have proposed or developed risk assessment methods, but they all focus on quantitative or qualitative methods, and the application process is complicated, which often cannot meet the requirements of batch high accuracy analysis of risk factors of domestic gas wells. Based on the above situation, a set of rapid semi-quantitative risk assessment methods for gas wells is proposed by combining the existing risk assessment methods with the rapid risk assessment method of annulus well killing in Chevron Company, taking into account the scientificity and operability. The idea of rapid semi-quantitative risk assessment for high-pressure gas wells is as follows: Firstly, the well barrier status of 
gas wells is graded and the annulus pressure of gas wells is preliminarily analyzed. If the well barrier is classified as yellow or green, and the total score of the preliminary analysis of annulus pressure is 0 , the well integrity risk level is low, and no subsequent risk analysis is needed. Otherwise, further well integrity risk analysis is conducted. For wells that cannot be judged as low risk by preliminary classification of well integrity risk level, rapid semi-quantitative risk assessment is carried out considering the main risk factors of gas well annulus pressure.

\section{Preliminary Analysis of Well Integrity Risk}

\subsection{Well Barrier Classification}

The fast qualitative classification of well barrier conditions is carried out, and the classification principles are shown in Table 1 . According to the integrity of the well barrier to conduct a preliminary screening analysis, the basic overview of the well barrier status.

\subsection{Preliminary Analysis of Annulus Pressure}

The analysis of annulus pressure is carried out for all annulus to determine whether the annulus pressure is abnormal. The discriminant principles are shown in Table 2. According to the preliminary analysis of annulus pressure, the basic profile of annulus pressure is obtained.

\subsection{Preliminary Classification of Well Integrity Risk}

Through the preliminary analysis of well barrier classification and annulus pressure, it is concluded that:

1) If the well barrier is classified as yellow or green and the total score of the preliminary analysis of annulus pressure is 0 , the well integrity risk level is low and no subsequent risk analysis is required;

2) Otherwise, do further well integrity risk analysis.

\section{Rapid Semi-Quantitative Risk Assessment}

Considering the main risk factors of gas well annulus pressure, a rapid semiquantitative risk assessment method is established for wells whose integrity risk level cannot be judged as low risk. The main factors include that:

Table 1. Well classification principle.

\begin{tabular}{cl}
\hline Level & \multicolumn{1}{c}{ Principle } \\
\hline Red & $\begin{array}{l}\text { One well barrier fails, another well barrier degenerates or fails, or leakage has } \\
\text { occurred to the ground. }\end{array}$ \\
Orange & $\begin{array}{l}\text { One well barrier fails, another well barrier is intact, or a single failure may lead to } \\
\text { leakage to the ground. }\end{array}$ \\
Yellow & One well barrier degradation, another well barrier intact. \\
Green & Two wells are well protected or have minor problems.
\end{tabular}


Table 2. Preliminary analysis principle of annulus pressure.

\begin{tabular}{|c|c|c|c|}
\hline annulus & pressure value & status & score \\
\hline \multirow{2}{*}{ Annulus A } & Minimum reserve pressure - Maximum & YES & 0 \\
\hline & recommended pressure & NO & 1 \\
\hline \multirow{2}{*}{ Annulus B } & $0.7 \mathrm{MPa}$ - Maximum recommended pressure of & YES & 0 \\
\hline & Annulus B & NO & 1 \\
\hline \multirow{2}{*}{ Annulus $\mathrm{C}$} & $0.7 \mathrm{MPa}$ - Maximum recommended pressure of & YES & 0 \\
\hline & Annulus C & NO & 1 \\
\hline \multirow{2}{*}{ Annulus D } & $0.7 \mathrm{MPa}$ - Maximum recommended pressure of & YES & 0 \\
\hline & Annulus D & NO & 1 \\
\hline \multirow{3}{*}{ Annulus $\mathrm{E}$} & $0.7 \mathrm{MPa}$ - Maximum recommended pressure of & YES & 0 \\
\hline & Annulus E & NO & 1 \\
\hline & Total Score & & $x \times$ \\
\hline
\end{tabular}

Tips: If the annular pressure of $\mathrm{A}$ is lower than the minimum reserved pressure or the inter-casing annular pressure is lower than $0.7 \mathrm{Mpa}$, and it can be proved that the integrity of the annulus is intact and there is no risk of leakage, then 0 marks can be given.

1) All annulus pressure values;

2) Well service life;

3) Recovery of annular pressure after pressure relief;

4) Reservoir conditions (formation pressure, production);

5) $\mathrm{CO}_{2}$ and $\mathrm{H}_{2} \mathrm{~S}$ content.

Fully considering the above factors, establish a set of rapid semi-quantitative risk assessment method, the specific quantitative scoring principle is shown in Table 3.

In addition to scoring according to Table 3 above, the additional risks caused by continuous annulus pressure should be fully considered. The additional scoring principle of continuous annulus pressure is shown in Table 4.

After completing the fast quantitative scoring of gas wells, according to the fast semi-quantitative risk classification principle shown in Table 5 below, the risk level is divided.

For fast semi-quantitative risk assessment results for high and high risk wells, it is recommended to carry out further discussion and analysis, or to carry out quantitative risk assessment according to needs.

\section{Calculation and Analysis of Case Wells}

A well, the annulus pressure of $\mathrm{A}, \mathrm{B}$ and $\mathrm{C}$ is continuous and can release combustible gas. The analysis shows that the annulus pressure of reservoir gas A can be stabilized between the minimum reserve pressure and the maximum recommended pressure. The annulus pressure of $\mathrm{C}$ exceeds the maximum recommended pressure, but is less than the maximum allowable pressure. The annulus pressure of $\mathrm{D}$ is $1 \mathrm{MPa}$. The rapid analysis process of the well is as follows: 
Table 3. Fast semi-quantitative scoring principle.

\begin{tabular}{|c|c|c|c|c|}
\hline Risk Factor & Parameter & Score & Weight & Total Score \\
\hline \multirow{5}{*}{$\begin{array}{l}\text { Pressure of } \\
\text { Annulus A }\end{array}$} & $\geq$ Maximum limit pressure & 8 & 5 & 40 \\
\hline & Maximum limit pressure $>x>$ Maximum allowable pressure & 3 & 5 & 15 \\
\hline & Maximum allowable pressure $>X>$ Maximum recommended pressure & 2 & 5 & 10 \\
\hline & Maximum recommended pressure $>x>$ Minimum reserve pressure & 0 & 5 & 0 \\
\hline & Minimum reserve pressure $>x \geq$ Minimum limit pressure & 8 & 5 & 40 \\
\hline \multirow{5}{*}{$\begin{array}{l}\text { Pressure of } \\
\text { Annulus B }\end{array}$} & $\geq$ Maximum limit pressure & 8 & 4 & 32 \\
\hline & Maximum limit pressure $>x>$ Maximum allowable pressure & 3 & 4 & 12 \\
\hline & Maximum allowable pressure $>x>$ Maximum recommended pressure & 2 & 4 & 8 \\
\hline & Maximum recommended pressure $>x>0.7 \mathrm{MPa}$ & 0 & 4 & 0 \\
\hline & $0.7>x \geq 0 \mathrm{MPa}$ & 3 & 4 & 12 \\
\hline \multirow{5}{*}{$\begin{array}{l}\text { Pressure of } \\
\text { Annulus C }\end{array}$} & $\geq$ Maximum limit pressure & 8 & 4 & 32 \\
\hline & Maximum limit pressure $>x>$ Maximum allowable pressure & 3 & 4 & 12 \\
\hline & Maximum allowable pressure $>x>$ Maximum recommended pressure & 2 & 4 & 8 \\
\hline & Maximum recommended pressure $>x>0.7 \mathrm{MPa}$ & 0 & 4 & 0 \\
\hline & $0.7>x \geq 0 \mathrm{MPa}$ & 3 & 4 & 12 \\
\hline \multirow{5}{*}{$\begin{array}{l}\text { Pressure of } \\
\text { Annulus D }\end{array}$} & $\geq$ Maximum limit pressure & 8 & 3 & 24 \\
\hline & Maximum limit pressure $>x>$ Maximum allowable pressure & 3 & 3 & 9 \\
\hline & Maximum allowable pressure $>x>$ Maximum recommended pressure & 2 & 3 & 6 \\
\hline & Maximum recommended pressure $>x>0.7 \mathrm{MPa}$ & 0 & 3 & 0 \\
\hline & $0.7>x \geq 0 \mathrm{MPa}$ & 3 & 3 & 9 \\
\hline \multirow{5}{*}{$\begin{array}{l}\text { Pressure of } \\
\text { Annulus E }\end{array}$} & $\geq$ Maximum limit pressure & 8 & 3 & 24 \\
\hline & Maximum limit pressure $>X>$ Maximum allowable pressure & 3 & 3 & 9 \\
\hline & Maximum allowable pressure $>x>$ Maximum recommended pressure & 2 & 3 & 6 \\
\hline & Maximum recommended pressure $>x>0.7 \mathrm{MPa}$ & 0 & 3 & 0 \\
\hline & $0.7>x \geq 0 \mathrm{MPa}$ & 3 & 3 & 9 \\
\hline \multirow{5}{*}{ Service life of well } & $\leq 5$ years & 1 & 1 & 1 \\
\hline & $5-10$ years & 3 & 1 & 3 \\
\hline & $10-15$ years & 5 & 1 & 5 \\
\hline & $15-20$ years & 7 & 1 & 7 \\
\hline & $\geq 20$ years & 9 & 1 & 9 \\
\hline \multirow{2}{*}{ Gas well condition } & Closing-in & 1 & 2 & 2 \\
\hline & Producing & 2 & 2 & 4 \\
\hline \multirow{4}{*}{ Formation pressure } & $\geq 140 \mathrm{MPa}$ & l & l & 7 \\
\hline & $140 \mathrm{MPa}>x \geq 105 \mathrm{MPa}$ & l & l & 5 \\
\hline & $105 \mathrm{MPa}>x \geq 70 \mathrm{MPa}$ & l & l & 3 \\
\hline & $<70 \mathrm{MPa}$ & l & l & 1 \\
\hline \multirow{4}{*}{ Production } & $\geq 200 \times 10^{4} \mathrm{~m}^{3} /$ day & l & l & 7 \\
\hline & $200 \times 10^{4} \mathrm{~m}^{3} /$ day $>x \geq 100 \times 10^{4} \mathrm{~m}^{3} /$ day & l & l & 5 \\
\hline & $100 \times 10^{4} \mathrm{~m}^{3} /$ day $>x \geq 50 \times 10^{4} \mathrm{~m}^{3} /$ day & l & l & 3 \\
\hline & $<50 \times 10^{4} \mathrm{~m}^{3} /$ day & 1 & 1 & 1 \\
\hline
\end{tabular}


Table 4. Additional scores principle of continuous annulus pressure well.

\begin{tabular}{|c|c|c|c|c|c|}
\hline Risk Factor & Parameter & Score & Weight & Total Score & Tips \\
\hline \multirow{5}{*}{$\begin{array}{c}\text { Recovery after pressure relief } \\
\text { annulus A }\end{array}$} & $>24$ Hours & 0 & 5 & 0 & l \\
\hline & 24 Hours $\geq X>60$ Minutes & 1 & 5 & 5 & I \\
\hline & 60 Minutes $\geq X>15$ Minutes & 3 & 5 & 15 & I \\
\hline & 15 Minutes $\geq X>1$ Minute & 4 & 5 & 20 & l \\
\hline & $\leq 1$ Minute & 6 & 5 & 30 & l \\
\hline \multirow{4}{*}{$\begin{array}{l}\text { Recovery after pressure relief } \\
\text { annulus B }\end{array}$} & $>24$ Hours & 0 & 5 & 0 & l \\
\hline & 24 Hours $\geq X>60$ Minutes & 1 & 5 & 5 & l \\
\hline & 60 Minutes $\geq X>15$ Minutes & 3 & 5 & 15 & l \\
\hline & 15 Minutes $\geq X>1$ Minute & 4 & 5 & 20 & l \\
\hline \multirow{6}{*}{$\begin{array}{l}\text { Recovery after pressure relief } \\
\text { annulus } C\end{array}$} & $\leq 1$ Minute & 6 & 5 & 30 & l \\
\hline & $>24$ Hours & 0 & 5 & 0 & l \\
\hline & 24 Hours $\geq X>60$ Minutes & 1 & 5 & 5 & l \\
\hline & 60 Minutes $\geq X>15$ Minutes & 3 & 5 & 15 & l \\
\hline & 15 Minutes $\geq X>1$ Minutes & 4 & 5 & 20 & l \\
\hline & $\leq 1$ Minutes & 6 & 5 & 30 & l \\
\hline \multirow{4}{*}{$\begin{array}{l}\text { Recovery after pressure relief } \\
\text { annulus } \mathrm{E}\end{array}$} & $>24$ Hours & 0 & 5 & 0 & l \\
\hline & 24 Hours $\geq X>60$ Minutes & 1 & 5 & 5 & l \\
\hline & 60 Minutes $\geq X>15$ Minutes & 3 & 5 & 15 & I \\
\hline & 15 Minutes $\geq X>1$ Minute & 4 & 5 & 20 & I \\
\hline \multirow{6}{*}{$\begin{array}{l}\text { Recovery after pressure relief } \\
\text { annulus E }\end{array}$} & $\leq 1$ Minute & 6 & 5 & 30 & I \\
\hline & $>24$ Hours & 0 & 5 & 0 & I \\
\hline & 24 Hours $\geq X>60$ Minutes & 1 & 5 & 5 & l \\
\hline & 60 Minutes $\geq X>15$ Minutes & 3 & 5 & 15 & I \\
\hline & 15 Minutes $\geq X>1$ Minute & 4 & 5 & 20 & I \\
\hline & $\leq 1$ Minute & 6 & 5 & 30 & l \\
\hline \multirow{3}{*}{ Is there gas in Annulus A } & No gas & 0 & 3 & 0 & I \\
\hline & Shallow gas & 1 & 3 & 3 & I \\
\hline & Reservoir gas & 3 & 3 & 9 & l \\
\hline \multirow{3}{*}{ Is there gas in Annulus B } & No gas & 0 & 4 & 0 & l \\
\hline & Shallow gas & 1 & 4 & 4 & l \\
\hline & Reservoir gas & 3 & 4 & 12 & l \\
\hline \multirow{3}{*}{ Is there gas in Annulus $\mathrm{C}$} & No gas & 0 & 4 & 0 & l \\
\hline & Shallow gas & 1 & 4 & 4 & l \\
\hline & Reservoir gas & 3 & 4 & 12 & I \\
\hline \multirow{3}{*}{ Is there gas in Annulus D } & No gas & 0 & 5 & 0 & l \\
\hline & Shallow gas & 1 & 5 & 5 & l \\
\hline & Reservoir gas & 3 & 5 & 15 & l \\
\hline
\end{tabular}




\section{Continued}

\begin{tabular}{|c|c|c|c|c|c|}
\hline & No gas & 0 & 5 & 0 & / \\
\hline \multirow[t]{4}{*}{ Is there gas in Annulus E } & Shallow gas & 1 & 5 & 5 & l \\
\hline & Reservoir gas & 3 & 5 & 15 & / \\
\hline & Annulus A & 11 & $\mathrm{~S} \% / 10$ & $0-10$ & Reservoir gas in annulus \\
\hline & Annulus B & 2 & $\mathrm{~S} \% / 10$ & $0-20$ & Reservoir gas in annulus \\
\hline \multirow[t]{5}{*}{$\mathrm{CO}_{2}$ Content } & Annulus C & 3 & $\mathrm{~S} \% / 10$ & $0-30$ & Reservoir gas in annulus \\
\hline & Annulus D & 3 & $\mathrm{~S} \% / 10$ & $0-30$ & Reservoir gas in annulus \\
\hline & Annulus E & 3 & $\mathrm{~S} \% / 10$ & $0-30$ & Reservoir gas in annulus \\
\hline & Annulus A & 1 & $\mathrm{~S} \% / 10$ & $0-10$ & Reservoir gas in annulus \\
\hline & Annulus B & 2 & $\mathrm{~S} \% / 10$ & $0-20$ & Reservoir gas in annulus \\
\hline \multirow[t]{3}{*}{$\mathrm{H}_{2} \mathrm{~S}$ Content } & Annulus C & 3 & $\mathrm{~S} \% / 10$ & $0-30$ & Reservoir gas in annulus \\
\hline & Annulus D & 3 & $\mathrm{~S} \% / 10$ & $0-30$ & Reservoir gas in annulus \\
\hline & Annulus E & 3 & $\mathrm{~S} \% / 10$ & $0-30$ & Reservoir gas in annulus \\
\hline
\end{tabular}

Table 5. Fast semi-quantitative risk classification principles.

\begin{tabular}{cc}
\hline Risk level & Quantitative score \\
\hline Very High & $\geq 60$ \\
High & $40<x<60$ \\
Medium & $20<x<40$ \\
Low & $\leq 20$ \\
\hline
\end{tabular}

1) Through the well barrier analysis found that: the first well barrier degradation, there is slight leakage, the second well barrier is intact, well barrier classification is yellow.

2) Through the preliminary analysis of annulus pressure: A annulus score is 0 , $\mathrm{B}$ annulus score is $1, \mathrm{C}$ annulus score is $1, \mathrm{D}$ annulus score is 0 .

Combined with well barrier analysis and annulus pressure preliminary analysis, it is concluded that the well needs further risk analysis.

3) Fully considering the current situation of the well, rapid semi-quantitative risk assessment is carried out, and the specific quantitative scoring is shown in Table 6.

Table 6. Quick semi-quantitative scoring table of a well.

\begin{tabular}{|c|c|c|c|c|}
\hline Risk factor & Parameter & Score & Weight & Total score \\
\hline Pressure of Annulus E & $\begin{array}{c}\text { Maximum recommended pressure }>x>\text { Minimum } \\
\text { reserve pressure }\end{array}$ & 0 & 5 & 0 \\
\hline Pressure of Annulus E & $\begin{array}{c}\text { Maximum allowable pressure }>x>\text { Maximum } \\
\text { recommended pressure }\end{array}$ & 2 & 4 & 8 \\
\hline Pressure of Annulus E & $\begin{array}{c}\text { Maximum allowable pressure }>x>\text { Maximum } \\
\text { recommended pressure }\end{array}$ & 2 & 4 & 8 \\
\hline
\end{tabular}




\section{Continued}

\begin{tabular}{|c|c|c|c|c|}
\hline Pressure of Annulus E & Maximum recommended pressure $>x>0.7 \mathrm{MPa}$ & 0 & 3 & 0 \\
\hline Service life of well & $10-15$ Years & 5 & 1 & 5 \\
\hline Gas well condition & Producing & 2 & 2 & 4 \\
\hline Formation pressure & $105 \mathrm{MPa}>x \geq 70 \mathrm{MPa}$ & l & l & 3 \\
\hline Production & $100 \times 10^{4} \mathrm{~m}^{3} /$ day $>x \geq 50 \times 10^{4} \mathrm{~m}^{3} /$ day & l & l & 3 \\
\hline Recovery after pressure relief annulus E & $>24$ Hours & 0 & 5 & 0 \\
\hline Recovery after pressure relief annulus E & 24 Hours $\geq X>60$ Minutes & 1 & 5 & 5 \\
\hline Recovery after pressure relief annulus $\mathrm{E}$ & 24 Hours $\geq X>60$ Minutes & 1 & 5 & 5 \\
\hline Is there gas in Annulus A & Reservoir gas & 3 & 3 & 9 \\
\hline Is there gas in Annulus B & Reservoir gas & 3 & 4 & 12 \\
\hline Is there gas in Annulus $\mathrm{C}$ & Reservoir gas & 3 & 4 & 12 \\
\hline & Sum & & & 74 \\
\hline
\end{tabular}

The result of fast quantitative scoring of a well is 74 , the total score is higher than 60, and the risk level is very high. Quantitative risk assessment and detailed diagnostic analysis are recommended.

\section{Conclusions}

1) Considering the well barrier and annulus pressure of high temperature and high pressure gas wells, a rapid semi-quantitative risk assessment method for high temperature and high pressure gas wells is established, which takes annulus pressure value, well service life, annulus pressure recovery after pressure relief, reservoir conditions and well $\mathrm{CO}_{2}$ and $\mathrm{H}_{2} \mathrm{~S}$ content as the key risk indexes. It provides important technical guidance for the safe production of gas.

2) The risk value and risk grade of a practical well were evaluated semi-quantitatively. The results show that the score of the well is 74, the total score is higher than 60, and the risk grade is very high. Quantitative risk assessment and detailed diagnostic analysis are recommended.

\section{Conflicts of Interest}

The authors declare no conflicts of interest regarding the publication of this paper.

\section{References}

[1] Abou-Sayed, A.S., Noble, J.E., Guo, Q., et al. (2002) Application of Risk Analysis to Assessment of Casing Integrity and Subsidence in Deepwater Reservoirs. SPE/ISRM Rock Mechanics Conference, Irving, October 2002, SPE-78216-MS. https://doi.org/10.2118/78216-MS

[2] Al-Ashhab, J. and Afzal, M. (2004) Well Integrity Management System (WIMS). The 11 th $A b u$ Dhabi International Petroleum Exhibition and Conference, Abu Dhabi, 10-13 October 2004, SPE-88696-MS. https://doi.org/10.2118/88696-MS 
[3] Noori, S.A. and Price, J.W.H. (2006) A Risk Approach to the Management of Boiler Tube Thinning. Nuclear Engineering and Design, 236, 405-414. https://doi.org/10.1016/j.nucengdes.2005.09.019

[4] Seyed-Hosseini, S.M., Safaei, N. and Asgharpour, M.J. (2006) Reprioritization of Failures in a System Failure Mode and Effects Analysis by Decision Making Trial and Evaluation Laboratory Technique. Reliability Engineering \& System Safety, 91, 872-881. https://doi.org/10.1016/j.ress.2005.09.005

[5] Wallace, G.C., Kiddie, N., Kearns, J., et al. (2008) A Compliance Based Approach to Well Integrity Management. SPE Annual Technical Conference and Exhibition, Denver, September 2008, SPE-115585-MS.

https://doi.org/10.2118/115585-MS

[6] Seyed-Hosseini, S.M., Safaei, N. and Asgharpour, M.J. (2006) Reprioritization of Failures in a System Failure Mode and Effects Analysis by Decision Making Trial and Evaluation Laboratory Technique. Reliability Engineering \& System Safety, 91, 872-881. https://doi.org/10.1016/j.ress.2005.09.005

[7] Sultan, A. (2009) Well Integrity Management Systems; Achievements versus Expectations. International Petroleum Technology Conference.

[8] Freij-Ayoub, R. (2009) Casing Integrity in Hydrate Bearing Sediments. 43rd US Rock Mechanics Symposium \&4th US-Canada Rock Mechanics Symposium.

[9] Dethlefs, J. and Chastain, B. (2012) Assessing Well-Integrity Risk: A Qualitative Model. SPE Drilling \& Completion, 27, 294-302. https://doi.org/10.2118/142854-PA

[10] Feng, W., Yu, L.C., Qing, L., et al. (2013) Risk Assessment Technology Research on Co-Injection Wellbore. SPE Asia Pacific Oil and Gas Conference and Exhibition, Jakarta, October 2013, SPE-165745-MS. https://doi.org/10.2118/165745-MS

[11] Rocha-Valadez, T., Hasan, A.R., Mannan, S., et al. (2014) Assessing Wellbore Integrity in Sustained-Casing-Pressure Annulus. SPE Drilling \& Completion, 29, 131-138. https://doi.org/10.2118/169814-PA

[12] Helvacioglu, S. and Ozen, E. (2014) Fuzzy Based Failure Modes and Effect Analysis for Yacht System Design. Ocean Engineering, 79, 131-141. https://doi.org/10.1016/j.oceaneng.2013.12.015

[13] Abimbola, M., Khan, F. and Khakzad, N. (2016) Risk-Based Safety Analysis of Well Integrity Operations. Safety Science, 84, 149-160.

https://doi.org/10.1016/j.ssci.2015.12.009

[14] Ramzali, N., Lavasani, M.R.M. and Ghodousi, J. (2015) Safety Barriers Analysis of Offshore Drilling System by Employing Fuzzy Event Tree Analysis. Safety Science, 78, 49-59. https://doi.org/10.1016/j.ssci.2015.04.004

[15] Brandt, H. (2016) Well Integrity Management-Application of Risk Assessment to Optimize Your Decisions. Offshore Technology Conference Asia, Kuala Lumpur, March 2016, OTC-26817-MS. https://doi.org/10.4043/26817-MS 